\title{
REGIONALIZAÇÃO DAS TEMPERATURAS MÍNIMAS DO AR PREJUDICIAIS À FECUNDAÇÃO DAS FLORES DE ARROZ PARA A REGIÃO CLIMÁTICA DA DEPRESSÃO CENTRAL, RS
}

\author{
MINIMUM AIR TEMPERATURES PROBABILITIES HARMFUL TO THE FECUNDATION OF RICE \\ FLOWERS IN THE CENTRAL REGION OF RIO GRANDE DO SUL, BRAZIL
}

\author{
Galileo Adeli Buriol ${ }^{1}$ Valduíno Estefanel ${ }^{1}$ Sílvio Steinmetz ${ }^{2}$ \\ Jacques Leandro Schvambach ${ }^{3}$ Marino Antônio Didone ${ }^{3}$
}

\section{RESUMO}

Foram mapeadas as probabilidades de ocorrência de temperaturas mínimas do ar prejudiciais à fecundação das flores de arroz na Região Climática da Depressão Central do Estado do Rio Grande do Sul. Utilizaram-se os valores de probabilidade de ocorrência de temperaturas mínimas do ar iguais ou inferiores a 13,15 e $17^{\circ} \mathrm{C}$ em um ou mais dias, cinco ou mais dias e dei ou mais dias para os meses de dezembro, janeiro, fevereiro e março. As isolinhas de probabilidade foram traçadas em um mapa ipsométrico da região. Os resultados mostram que as menores probabilidades se situam nas partes de menor altitude como nos vales dos rios Ibicuí, Jacuí, Taquari, estuário do Guaíba e seus afluentes e que o período de menor periculosidade das temperaturas mínimas do ar ocorre nos meses de janeiro e fevereiro.

Palavras-chave: arroz, temperatura mínima, probabilidade, regionalização

\section{SUMMARY}

The probability of occurency of minimum air temperatures harmful to the fecundation of rice flowers in the Central Region of Rio Grande do Sul State was shown in a map. Minimum air temperatures lower or equal to 13,15 e $17^{\circ} \mathrm{C}$ occuring during one or more days, five or more days and ten or more days in December, Jannary, February and March were used. The isolines of probability were drown on a map. The results showed that the lower probabilities are located in the parts of the land with lower altitude like the valley of Ibicui, Jacui, Taquari, and Guaiba rivers. Besides, January and February are the months where the risks of low temperatures to rice flowering is lower.

Key words: rice, minimum temperature, probability, harmful.

\section{INTRODUÇÃO}

A quantificação das disponibilidades do número de dias com temperaturas mínimas do ar prejudiciais à fecundação das flores do arroz e da intensidade das mesmas é muito importante, principalmente para a recomendação de épocas de semeadura e de cultivares e para adoção de práticas culturais. Com esse objetivo, no Estado do Rio Grande do Sul, já foram determinadas as probabilidades de ocorrência do número de dias com temperaturas mínimas do ar iguais ou inferiores a 10,11, 12, 13, 14, 15,16 e $17^{\circ} \mathrm{C}$ para cada decêndio dos meses de dezembro, janeiro, fevereiro e março para Santa Maria (BURIOL et al., 1991), iguais ou inferiores a 13, 15 e $17^{\circ} \mathrm{C}$ para diferentes locais da Região Climática da Depressão Central (BURIOL et al., 1998) e das Regiões Climáticas do Litoral Sul, Campanha e Baixo Vale do Uruguai (STEINMETZ et al., 1995, 1997). Nesses trabalhos, os resultados, para cada local estão apresentados em forma de tabelas. Embora essa forma de apresentação permita obter os dados com bastante precisão e detalhes, possui o inconveniente dos valores serem pontuais, impossibilitando a visualização de sua distribuição geográfica.

Dessa forma, o presente trabalho objetiva representar, com o auxilio de mapas, a distribuição espacial das diferentes probabilidades de ocorrência

\footnotetext{
${ }^{1}$ Engenherio Agrônomo, Professor do Departamento de Fitotecnia, Bolsista CNPq, Centro de Ciências Rurais, Universidade Federal de Santa Maria (UFSM), 97105-900, Santa Maria - RS. Autor para correspondência.

${ }^{2}$ Engenherio Agrônomo, Doutor, Pesquisador do CPACT (EMBRAPA), CP 403, Pelotas - RS

${ }^{3}$ Acadêmico do Curso de Agronomia, Bolsista do PIBIC/CNPq e FAPERGS, UFSM.
} 
de temperaturas mínimas prejudiciais à fecundação das flores de arroz na Região Climática da Depressão Central do Estado do Rio Grande do Sul.

\section{MATERIAL E MÉTODOS}

Do mapa ipsométrico do Estado do Rio Grande do Sul, realizado pelo Conselho Nacional de Geografia e Estatística/Instituto Gaúcho de Reforma Agrária, ano de 1966, escala 1:750.000, foi desenhada a parte pertencente à Região Climatológica da Depressão Central. Procurou-se utilizar uma área na qual estivesse representada a maior parte da região delimitada por ARAÚJO (1930) e MACHADO (1950) como pertencente a esta Região Climática. Sobre esse mapa foram plotadas as probabilidades de ocorrência de temperaturas mínimas prejudiciais à fecundação das flores do arroz calculadas para nove estações meteorológicas (Porto Alegre, Cachoeirinha, Tapes, Eldorado do Sul, Taquari, Cachoeira do Sul, Santa Maria, São Gabriel e Alegrete) e traçadas as isolinhas de probabilidades.

As cartas foram traçadas considerando as temperaturas iguais ou inferiores a 13,15 e $17^{\circ} \mathrm{C}$ em um ou mais dias, 'em cinco ou mais dias e em dez ou mais dias para os meses de dezembro, janeiro, fevereiro e março. Elegeram-se esses limites térmicos considerando a temperatura diária do ar menor ou igual a $17^{\circ} \mathrm{C}$ como o limite térmico mais elevado na escala de intensidade de temperaturas prejudiciais, menor ou igual a $15^{\circ} \mathrm{C}$ como o limite térmico de referência, pois é a mais citada na literatura (SATAKE, 1969; BOARD et al., 1979; TERRES e GALLI, 1985) e menor ou igual a $13^{\circ} \mathrm{C}$ como limite térmico de alta periculosidade. A representação cartográfica de somente um ou mais dias, cinco ou mais dias e dez ou mais dias é justificada no sentido de não tornar o trabalho muito extenso. Pelo mesmo motivo não foram mapeados os dados decendiais, como seria interessante, mas somente os valores mensais. Os dados de probabilidade utilizados para as diferentes estações meteorológicas foram coletados de tabelas calculadas para o trabalho publicado por BURIOL et al., (1 998).

No traçado das isolinhas procurou-se levar em conta a influência dos fatores geográficos na distribuição das temperaturas, principalmente da altitude, continentalidade e latitude. Delimitaram-se as diferentes áreas de risco utilizando os limites de 0-20, 20-40, 40-60, 60-80 e 80-100\% de probabilidade de ocorrência.

\section{RESULTADOS E DISCUSSÃO}

As figuras 1 e 2 apresentam as cartas de probabilidade de ocorrência, respectivamente, de cinco ou mais dias e dez ou mais dias com temperaturas mínimas do ar iguais ou inferiores a $17^{\circ} \mathrm{C}$, para os meses de dezembro, janeiro, fevereiro e março. No caso de um (01) ou mais dias, em função dos quatro meses considerados e de toda a área da região climática da Depressão Central enquadrar-se na faixa de 80 a $100 \%$ dos anos com probabilidade de ocorrer temperaturas mínimas do ar iguais ou inferiores a $17^{\circ} \mathrm{C}$, considerouse desnecessária sua apresentação cartográfica. Ao considerar-se a probabilidade de ocorrência de cinco ou mais dias, figura 1 , as faixas de probabilidade se ampliam, observando-se áreas com probabilidades que vão de 60 a $100 \%$ em dezembro e março e de 20 a $100 \%$ em janeiro e fevereiro. Para a probabilidade de ocorrência de dez ou mais dias, figura 2, os limites se ampliam ainda mais alcançando valores de 20 a $100 \%$ em dezembro e março e de O (zero) a $100 \%$ em janeiro e fevereiro. Os dados das figuras 1 e 2 , além de mostrarem que a probabilidade de ocorrência de temperaturas mínimas iguais ou inferiores a $17^{\circ} \mathrm{C}$ diminui com o aumento do número de dias considerados, permitem ainda observar que as menores probabilidades são verificadas no leste da Depressão Central e junto aos vales dos rios Ibicuí, Jacuí, Taquari e junto ao estuário do Guaíba e seus afluentes, aumentando à medida que se afasta de suas margens, tanto ao norte como ao sul.

A distribuição geográfica das áreas com as diferentes probabilidades de ocorrência, respectivamente, de um (01) ou mais dias, cinco ou mais dias e dez ou mais dias com temperaturas mínimas do ar iguais ou inferiores a $15^{\circ} \mathrm{C}$, figuras 3,4 e 5 , e de um (01) ou mais dias e cinco ou mais dias iguais ou inferiores a $13^{\circ} \mathrm{C}$, figuras 6 e 7 , para os meses de dezembro, janeiro, fevereiro e março é semelhante àquela verificada com as temperaturas iguais ou inferiores a $17^{\circ} \mathrm{C}$ : os menores valores de probabilidade ocorrendo no leste da Depressão Central e junto aos vales dos rios Ibicuí, Jacuí, Taquari e estuário do Guaíba e seus afluentes e aumentando com o afastamento das suas margens, tanto para norte como para o sul, as maiores probabilidades sendo observadas nas partes mais altas, principalmente nos rebordos das Serras do Nordeste, Sudeste e Planalto. Na parte central da Região Climática da Depressão Central, área compreendida entre a bacia hidrográfica do rio Jacuí e Ibicui, devido principalmente ao aumento da altitudeem relação às áreas dos vales desses rios, observa-se uma maior probabilidade de ocorrer temperaturas mínimas prejudiciais à fecundação das flores de arroz. Ainda, como se pode verificar nas figuras 3 a 7 , a probabilidade de ocorrência de temperaturas mínimas do ar iguais ou inferiores a 15 e $13^{\circ} \mathrm{C}$ diminui com o aumento do número de dias considerados. Observase, por exemplo, que para um ou mais dias com 


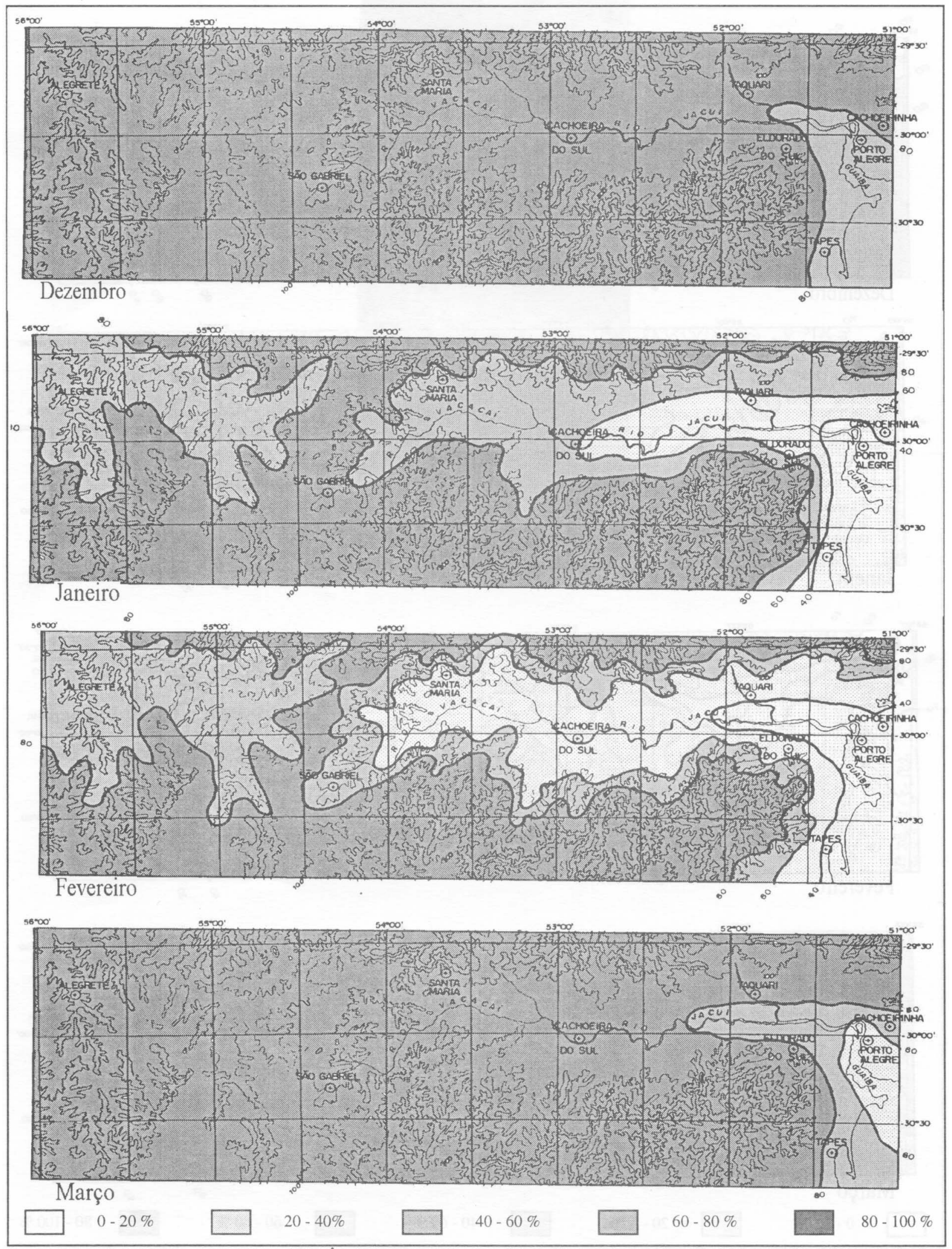

Figura 1 - Probabilidade de ocorrência de cinco ou mais dias com temperatura mínima do ar igual ou inferior a $17^{\circ} \mathrm{C}$ nos meses de dezembro, janeiro, fevereiro e março na Região Climática da Depressão Central, Estado do Rio Grande do Sul.

Ciência Rural, v. 30, n. 1, 2000. 

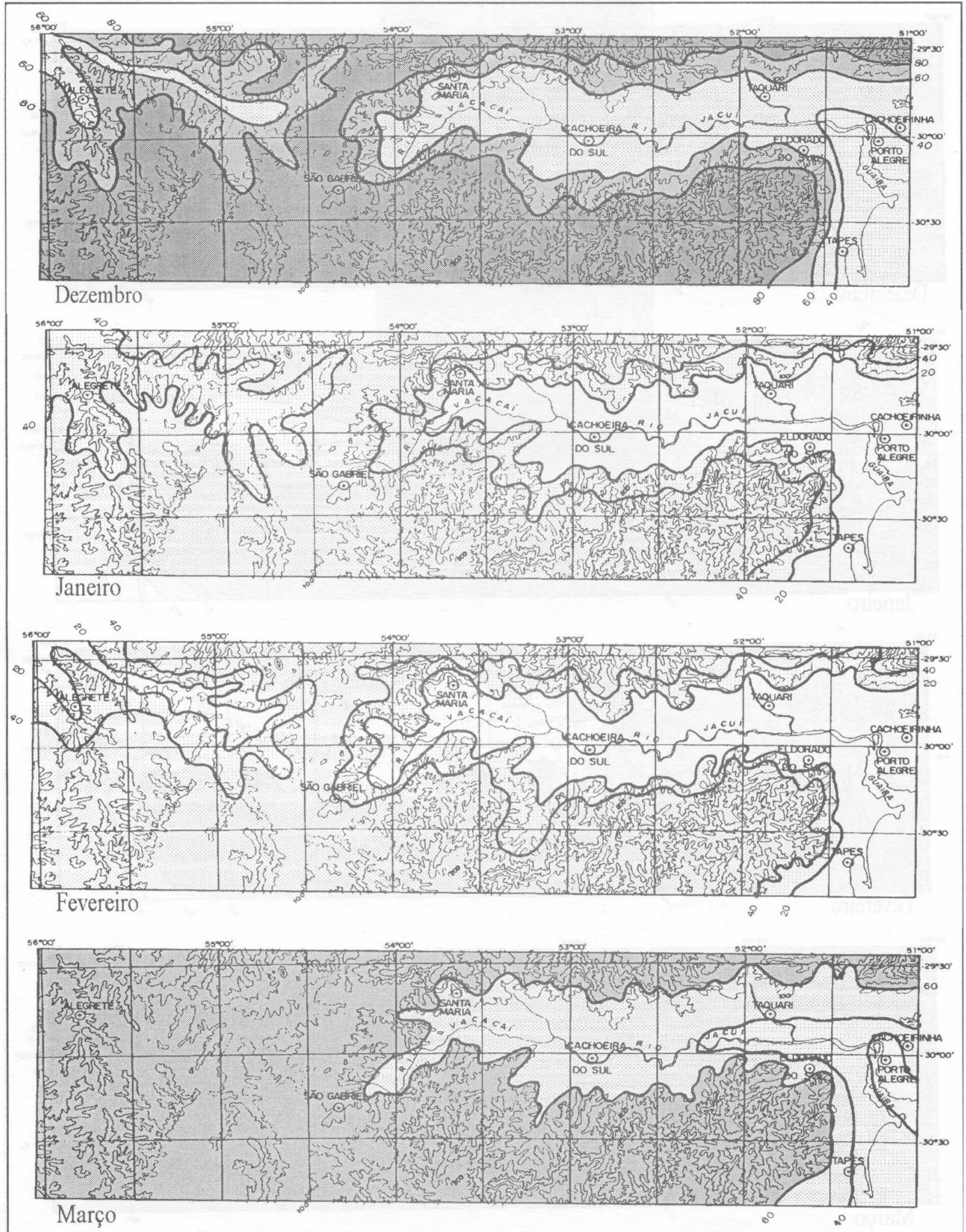
$\square \quad 0-20 \%$
$20-40 \%$
$40-60 \%$
$60-80 \%$
$80-100 \%$

Figura 2 - Probabilidade de ocorrência de dez ou mais dias com temperatura mínima do ar igual ou inferior a $17^{\circ} \mathrm{C}$ nos meses de dezembro, janeiro, fevereiro e março na Região Climática da Depressão Central, Estado do Rio Grande do Sul.

Ciência Rural, v. 30, n. 1, 2000. 


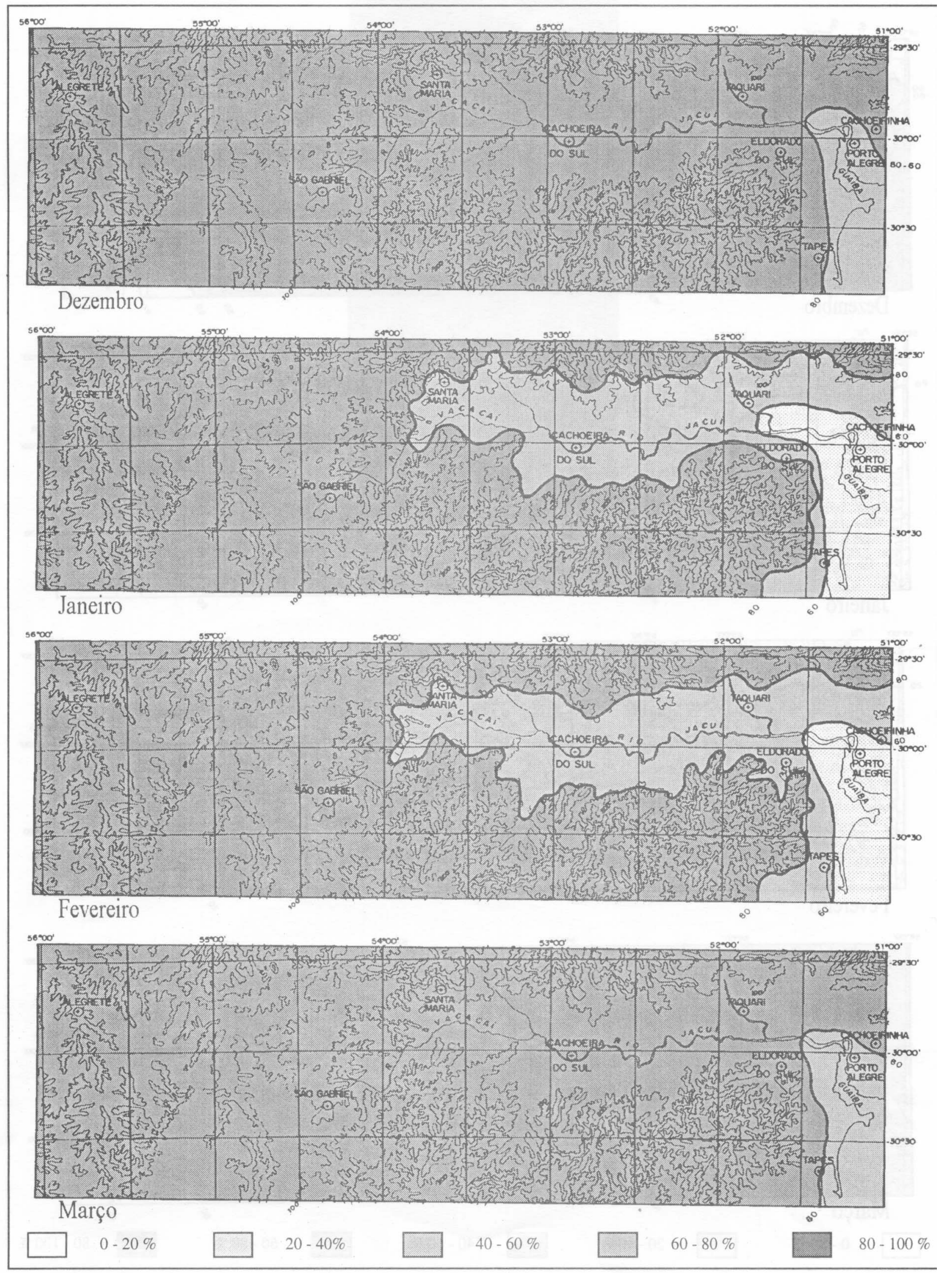

Figura 3 - Probabilidade de ocorrência de um ou mais com temperatura mínima do ar igual ou inferior a $15^{\circ} \mathrm{C}$ nos meses de dezembro, janeiro, fevereiro e março na Região Climática da Depressão Central, Estado do Rio Grande do Sul. 

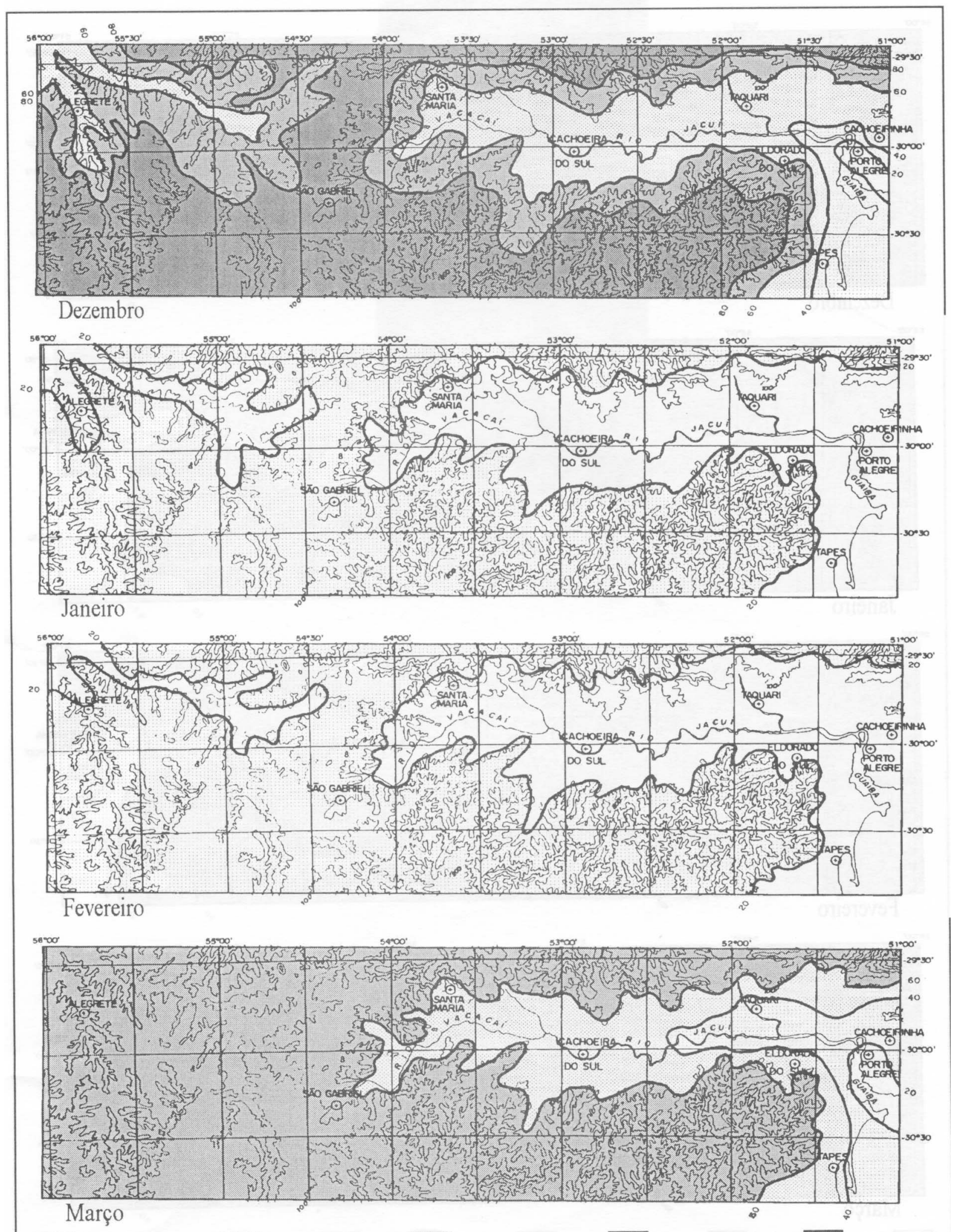

Figura 4 - Probabilidade de ocorrência de cinco ou mais dias com temperatura mínima do ar igual ou inferior a $15^{\circ} \mathrm{C}$ nos meses de dezembro, janeiro, fevereiro e março na Região Climática da Depressão Central, Estado do Rio Grande do Sul.

Ciência Rural, v. 30, n. 1, 2000. 


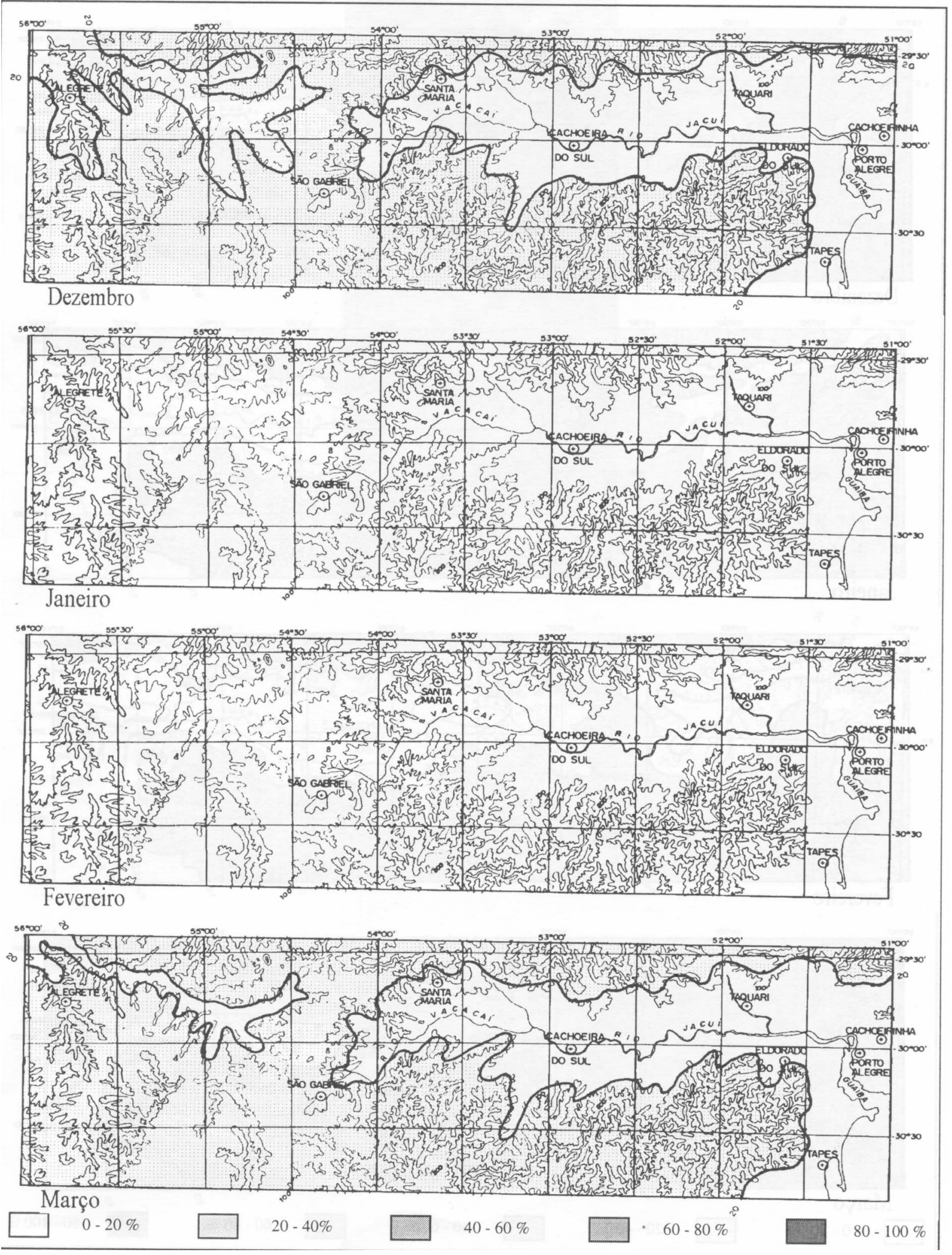

Figura 5 - Probabilidade da ocorrência de dez ou mais dias com temperatura mínima igual ou inferior a $15^{\circ} \mathrm{C}$ nos meses de dezembro, janeiro, fevereiro e março no Região Climática da Depressão Central, Estado do Rio Grande do Sul.

Ciência Rural, v. 30, n. 1, 2000. 

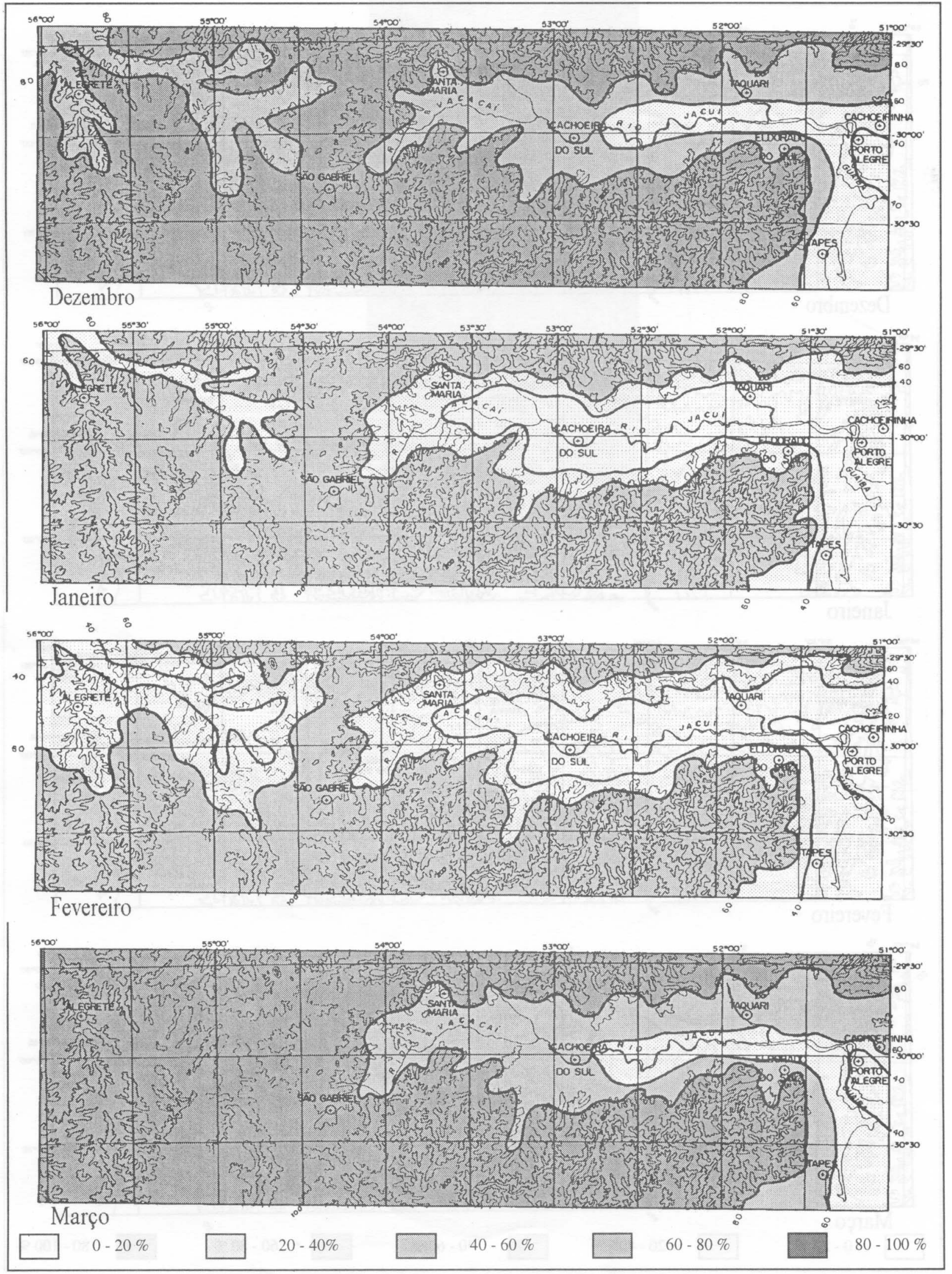

Figura 6 - Probabilidade de ocorrência de um ou mais dias com temperatura mínima do ar igual ou inferior a $13^{\circ} \mathrm{C}$ nos meses de dezembro, janeiro, fevereiro e março na Região Climática da Depressão Central, Estado do Rio Grande do Sul.

Ciência Rural, v. 30, n. 1, 2000. 

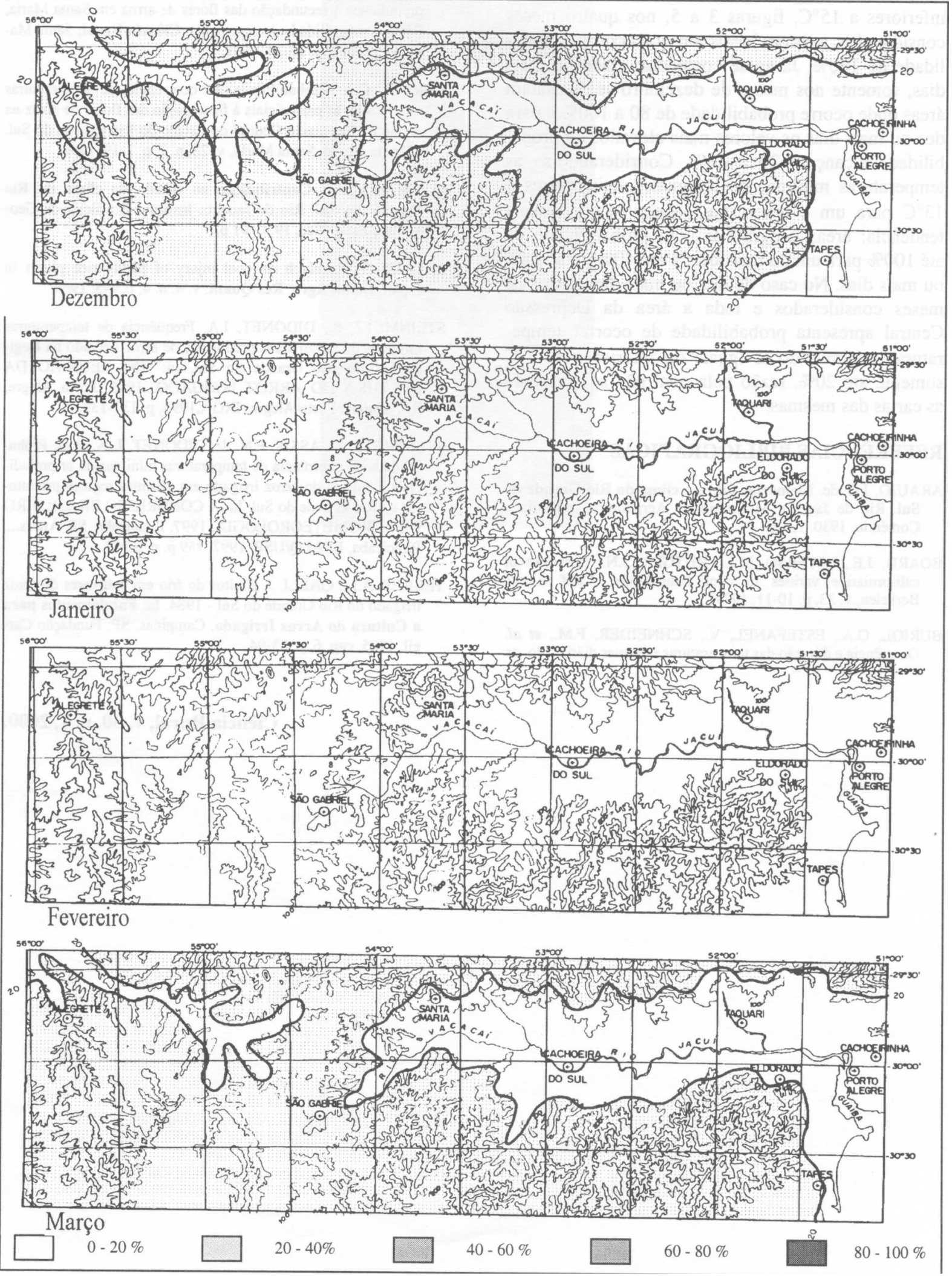

Figura 7 - Probabilidade de ocorrência de cinco ou mais dias com temperatura, mínima do ar igual ou inferior a $13^{\circ} \mathrm{C}$ nos meses de dezembro, janeiro, fevereiro e março na Região Climática da Depressão Central, Estado do Rio Grande do Sul.

Ciência Rural, v. 30, n. 1, 2000. 
temperaturas iguais ou inferiores a $15^{\circ} \mathrm{C}$, figuras 3 a 5 , nos quatro meses considerados, existem locais em que ocorre probabilidade de $100 \%$. Já ao se considerar cinco ou mais dias, somente nos meses de dezembro se constatam áreas onde ocorre probabilidade de 80 a $100 \%$ e para dez ou mais dias os valores mais elevados de probabilidade alcançam 20 a 40\%. Considerandose as temperaturas mínimas do ar iguais ou inferiores a $13^{\circ} \mathrm{C}$ para um e cinco dias, observa-se a mesma endência: áreas geográficas com probabilidade de até $100 \%$ para um ou mais dias e até $40 \%$ para cinco ou mais dias. No caso de dez ou mais dias, todos os meses considerados e toda a área da Depressão Central apresenta probabilidade de ocorrer temperaturas mínimas do ar iguais ou inferiores a $13^{\circ} \mathrm{C}$ somente até $20 \%$, razão pela qual não se apresenta as cartas das mesmas.

\section{REFERÊNCIAS BIBLIOGRÁFICAS}

ARAÚJO, J.C. de. Memórias sobre o clima do Rio Grande do Sul. Rio de Janeiro: Ministério da Agricultura, Industria e Comércio, 1930. 101p.

BOARD, J.E., PETERSO, M.L., RUTGER, J.N., Response of californiarice varities to cool temperature. Calif Agric, Berkeleu, v.33, p.10-11, 1979.

BURIOL, G.A., ESTEFANEL, V., SCHNEIDER, F.M., $\boldsymbol{e} \boldsymbol{t}$ al. Ocorrência e duração das temperaturas mínimas diárias do ar prejudiciais à fecundação das flores de arroz em Santa Maria, RS. 1- Probabilidade de ocorrência. Ciência Rural, Santa Maria, v.21, n.1, p.23-34, 1991.

BURIOL, G.A. Probabilidade de ocorrência de temperaturas mínimas do ar prejudiciais à fecundação das flores de arroz na região da Depressão Central do Estado do Rio Grande do Sul. Ciência Rural, Santa Maria, v.28, n.1, p.1-19,1998.

MACHADO, F.P. Contribuição ao estudo do clima do Rio Grande do Sul. Rio de Janeiro: Instituto Brasileiro de Geografia e Estatística, 1950. 91p.

STEINMETZ, S., DIDONET, I.A. Frequência de temperaturas mínimas do ar em áreas produtoras de arroz irrigado na Região Sul do Rio Grande do Sul. In: XXI REUNIÃO DA CULTURA DO ARROZ IRRIGADO, 1995, Porto Alegre, RS, Anais... Porto Alegre: IRGA. 1995, p.137-139.

STEINMETZ, S., ASSIS, F.N. de, DIDONET, I.A. $\boldsymbol{e}$ t al. Probabilidade de ocorrência de temperaturas mínimas do ar prejudiciais à cultura do arroz irrigado em distintas regiões produtoras do Rio Grande do Sul. In: X CONGRESSO BRASILEIRO DE AGROMETEOROLOGIA, 1997, Piracicaba, SP. Anais... Piracicaba, ESALQ/USP, 1997, p.8083.

TERRES, A.L., GALLI, J. Efeitos do frio em cultivares de arroz irrigado no Rio Grande do Sul - 1984. In: Fundamentos para Cultura de Arroz Irrigado. Campinas, SP: Fundação Cargil, 1985, cap.6, p.83-94. 